\title{
Considerações acerca da lenda do pacto com o diabo (Lendo Freud e Patočka)
} \author{
JANAINA NAMBA
$\begin{gathered}\text { Doutora em filosofia da psicanálise } \\ \text { pela UFSCar. }\end{gathered}$
}

Resumo: Este artigo pretende a partir de dois textos, Uma neurose demoníaca do século XVII, de Freud, e O sentido do mito do pacto com o diabo, de Patočka, analisar alguns aspectos convergentes e divergentes entre a fenomenologia de Patočka e a psicanálise de Freud quanto ao tema do sentido do mito do pacto com o diabo.

Palavras-chaves: Freud, Patočka, fenomenologia, psicanálise.
AвSTRACT: This paper intents to anylise, as from the two texts $A$ demon neurosis of the seventeenth century, from Freud, and The meaning of the myth of the pact with the devil, from Patocka, some converging and divergent aspects between the phenomenology of Patočka and psychoanalysis of Freud on the subject of the meaning of the myth of the pact with the devil.

Keywords: Freud, Patočka, phenomenology, psychoanalysis.

Ao analisar o sentido do mito do pacto com o diabo, Jan Patočka ${ }^{1}$ se pergunta sobre o que sempre leva a um retorno do tema faustino e não cessa de inquietar poetas, pensadores, até mesmo o público leigo em geral. O que tanto nos fascina a esse respeito? E arrisca uma resposta, apesar de reconhecer que há o

1. Jan Patočka (1907-1977), filósofo tcheco responsável pela tradução da Fenomenologia do espírito e da Estética de Hegel, em 1960 e 1966 respectivamente. Tais traduções expressam justamente que suas preocupações se estendem para além da fenomenologia até alcançar a estética. Elas inspiram a reunião de uma série de ensaios, de diferentes datas, que são consagrados à arte e à própria cultura européia sob todas as formas, dentre eles se encontra "O sentido do pacto com o diabo: meditação sobre a lenda de Fausto" (1973). In: Patočka, J. L'ecrivain, son "objet". Algumas das outras obras do autor: O mundo natural como problema filosófico (1936); Uma introdução aos estudos da fenomenologia de Husserl (1965). 
risco de simplificar e empobrecer a significação viva do mito da "venda da alma imortal". ${ }^{2}$ Mas, como nos diz Patočka, o tema faustino é recorrente e inquietante; e sobre isso Freud, em 1923, nos descreve um caso de uma neurose demoníaca do século XVII.

Freud se pergunta sobre o motivo, não do fascínio relativo ao tema faustino, mais geral que leva as pessoas a estabelecerem um pacto com o diabo. Freud diz que normalmente o diabo oferece em troca da alma imortal muitas coisas apreciadas pelos homens, como riqueza, forças sobrenaturais, poderes artísticos e principalmente o gozo. O pintor Christoph Haizmann, após a morte de seu pai, em 1668, encontrando-se deprimido e melancólico, teria feito um pacto com o diabo para que esse fosse o substituto de seu pai. Esse caso foi primeiramente descrito pela igreja como sendo um caso de exorcismo bem sucedido e posteriormente foi descrito por Freud como um caso de "neurose demoníaca".

É a partir de dois textos, Uma neurose demoníaca do século $X V I I$, de Freud, e $O$ sentido do mito do pacto com o diabo, de Patočka, que analisaremos alguns aspectos convergentes e divergentes entre a fenomenologia de Patočka e a psicanálise de Freud quanto ao tema do pacto.

A lenda do Fausto é matéria de muitas representações na cultura européia. Encontramo-la, com Patočka, em poemas célebres, como o de Goethe, e em romances, como o de Thomas Mann; mas também em fontes menos conhecidas, como nos arquivos de monastérios, resgatada por Freud. O cruzamento dessas análises que, sob perspectivas diferentes, abordam, a partir de fontes de natureza distinta, um mesmo mito, parece-nos uma oportunidade instigante.

Comecemos por Patočka.

2. Patočka, J. L'ecrivain, son “objet”. Paris: P.O.L., 1992, p. 128. 
[A imortalidade] é considerada como aquilo que garante a continuação da existência para além de seus limites empíricos. Com efeito, pode servir de apoio a todo o tipo de fraqueza e aviltamento, e ainda, pode significar o encadeamento servil do espírito à vida. ${ }^{3}$

Patočka considera que, depois de Platão, a alma imortal seja o bem supremo do homem europeu, sendo ela não um estado de fato, mas um momento diferenciador que conduz a existência à maior intensidade. No entanto, a venda da imortalidade enquanto resposta às fraquezas mundanas é considerada inautêntica, uma incapacidade de renunciar a si mesmo, uma incapacidade de se desvencilhar do material vivo da existência humana, o que levaria então a "um encadeamento servil do espírito à vida". Patočka segue dizendo que uma venda como essa pode até ser legitima e desculpável, mas é uma negociação indigna do espírito, que é o órgão do olhar, o órgão da compreensão da diferenciação do ser e do não-ser, ou a essência da alma. ${ }^{4} \mathrm{O}$ espírito como órgão transitivo do olhar é capaz de reconhecer o outro e deste outro é que se tem um reconhecimento de si, ou seja, é por meio do estabelecimento de uma relação que passamos a existir. ${ }^{5}$ Qualquer negociação por uma alma imortal acaba por interromper a existência que Patočka toma por um movimento, o movimento do ser, que tem início desde a sua emergência enquanto tal até o seu próprio fim. $E$ a venda da imortalidade da alma por motivos não autênticos implicaria então renúncia do ser, o que quer dizer, nos termos da filosofia de Patočka, que há uma fragmentação da unidade que é por sua vez o próprio ser. "Com a finalidade de que alguma coisa seja, e seja manifesta, ela deve ser um" , e se a unidade se encontra fragmentada há também um esfacelamento da forma pela qual uma coisa se manifesta no mundo, isto é, a perda da unidade faz com que a

3. Idem, p. 130.

4. Idem, ibidem.

5. Patočka, J. Le monde naturel et le mouvement de l'existence humaine. Paris: Kluwer academic publishers, 1980, p. 36.

6. Patočka, J. apud Barbaras, R. Le mouvement de l'existence: Études sur la phénoménologie de Jan Patočka. Chatou: Les Éditions de La Transparance, 2007, p. 37. 
forma visível também se perca, faz com que se perca a forma ou a essência do aparecer, o que acarreta a perda da forma do ser. Pois uma coisa só aparece como totalidade quando se posiciona perante outras, ou seja, só passa a ser quando está em relação com outras coisas. Com o fim da unidade perde-se o modo de aparecer de uma coisa, a forma pela qual ela se mostra e, consequentemente, como se dispõe no conjunto de todas as outras. Nas palavras de Patočka,

cada coisa adquire sua figura - se delimita - se transforma em indivíduo ao se dispor à parte das outras coisas. Torna-se o traço fronteiriço frente a uma outra coisa. Essa definição é feita frente a todas as outras coisas, todas sendo co-definidas. Esse definir é o aparecer da coisa enquanto seu ser. A coisa não é apenas algo "em-si-mesmo", mas existe em meio a todas as outras, ela é em si mesma a sua própria relação de delimitação frente à totalidade de tudo aquilo que é. ${ }^{7}$

Patočka diferencia uma imortalidade inautêntica de outra, que seria autêntica. A imortalidade inautêntica, como vimos, é proveniente da inquietude e ansiedade durante a vida, enquanto a autêntica revela que o medo de uma existência absolutamente negativa viria suplantar o próprio medo da morte. É o que indica seu texto sobre a lenda Fausto.

O Fausto (de Goethe) não se engana na sua escolha enquanto tal, mas no que se segue de sua escolha. Ele é por demais fraco para a escolha que faz, ele não consegue alçar seu ser ao grau superior ao qual aspira; ele não se torna pura inteligência, mas mágico vulgar. ${ }^{8}$

Em outras palavras, Fausto não é induzido pela ansiedade ou pela inquietude a realizar o pacto com o diabo, ao contrário, ao buscar superioridade intelectual reafirma a forma e unidade de seu ser. Mas, ao passo que realiza o pacto, perde-se na sua escolha e se torna incapaz de sustentá-la, isto é, torna-se incapaz de con-

7. Patočka, J. apud Idem, p. 38.

8. Patočka, J. L'ecrivain, son "objet", p. 131. 
tinuar escolhendo seu próprio rumo, correndo o risco de ter uma imortalidade inautêntica e encadear seu espírito numa relação de servilismo à vida.

Se tomarmos agora o caso do pintor Christoph Haizmann, descrito por Freud, do ponto de vista da filosofia de Patočka, poderíamos dizer que se trata de um caso de imortalidade inautêntica. O pintor afirma ter feito um pacto com o diabo, sendo a história do pacto descrita tanto em latim, por um escrevente do monastério no qual o pintor se refugia após ter realizado o pacto, quanto em alemão, pelo punho do próprio pintor, na forma de diário. De acordo com a interpretação da psicanálise freudiana, o pacto fora estabelecido porque o diabo seria, para o pintor, o substituto de seu falecido pai. Este evento, causando grande tristeza e melancolia no pintor, teria feito com que ele não pudesse mais trabalhar ou exercer a sua arte. A melancolia acarretada pela morte de um ente querido teria sido tão intensa que inibiu a atividade criativa de Haizmann. $\mathrm{O}$ pacto com o diabo seria uma solução para pôr fim a essa inatividade.

O manuscrito avaliado por Freud encontrava-se na biblioteca do monastério de Mariazell, a sudoeste de Viena, por ser um caso de exorcismo ou uma suposta redenção milagrosa ocorrida por graça da Virgem Maria. Constava no manuscrito que o pintor fizera um pacto com o Diabo, no ano de 1668, e que o referido acordo teria um prazo de nove anos de duração. Antes do término do prazo, em 1677, o pintor dirigira-se até o santuário de Mariazell para tentar redimir-se e reverter o tal pacto, ainda que alegasse que o diabo nada lhe teria exigido em troca. $\mathrm{O}$ manuscrito se encontra na biblioteca catalogado como um caso de cura milagrosa da Virgem, mas o fato é que, nove meses depois, Haizmann deixa de se sentir bem e retorna ao santuário apresentando convulsões, queixando-se de sensações dolorosas e em estado de alucinação. Haizmann diz que o diabo vem tentá-lo, que o Cristo vem redimi-lo, que a Virgem lhe recomenda que dê ouvidos a este último, etc.

Do ponto de vista da psicanálise freudiana, o pacto com o diabo feito pelo pintor revela uma relação ambivalente de amor e ódio que o filho possuía com o pai. "O pai, seria a imagem primor- 
dial tanto de deus como do diabo." $\mathrm{O}$ pai, além de enaltecido e amado, cópia de um pai vivenciado na infância, período no qual as crianças normalmente o endeusam, é também hostilizado e desafiado, chegando a ser figurado como o próprio diabo. Para Freud, "não é insólito que um homem contraia pela morte do pai uma depressão melancólica e uma inibição para o trabalho". ${ }^{10} \mathrm{E}$, diante de um amor intenso - neurótico - dedicado ao pai, a tristeza, por ocasião do luto, pode muito bem evoluir para uma melancolia mais grave. $\mathrm{O}$ que talvez seja interessante ressaltar é que o luto transformado em melancolia provavelmente não ocorrera tanto pelo amor intenso quanto pela relação ambivalente e degradada do pintor com seu pai, que seria assim expressa em sua "neurose demoníaca". ${ }^{11}$

Como diz Freud em Luto e melancolia, "a ambivalência é também constitucional, isto é, ela se encontra atada em qualquer relação de amor estabelecida por este ego [melancólico] em particular, ou ainda ela emerge de experiências que envolvem a perda do objeto". ${ }^{12}$ Segundo a descrição que temos de Haizmann observa-se a experiência da perda de um objeto reconhecidamente ambivalente, a saber, o pai. E num conflito de ambivalência encontramos tanto o amor bem fundado quanto o ódio não menos justificado que se dirigem à mesma pessoa. "É sob a influência da ambivalência que o investimento sobre o objeto amado perdido passa para um estágio sádico". ${ }^{13}$ Isto quer dizer que na melancolia o amor destinado ao objeto perdido retorna ao ego, que por sua vez é tomado como objeto e então investido de maneira narcisista, ora de maneira a se identificar ao objeto pelo amor que lhe dedica, ora destinando-lhe ódio e desprezo. Neste último caso, vemos que o ego passa por reprovações e se

9. Freud, S. "Una neurosis demoníaca en el siglo XVII" (1922). In: Obras Completas. Vol. XIX. Buenos Aires: Amorrortu editores, 2003, p. 88.

10. Idem, p. 89.

11. Idem, ibidem.

12. Freud, S. "Mourning and melancholia". In: The Penguin Freud Reader. London: Penguin Books, 2006, p. 323.

13. Idem, p. 318. 
torna objeto de humilhação e insulto, para satisfação de impulsos sádicos a ele dirigidos. Tais impulsos sádicos, ao serem direcionados ao ego, são tomados como masoquistas, e então temos uma das formas de masoquismo que se revela como sentimento de culpa, o masoquismo moral. Os impulsos direcionados ao ego são impulsos de destruição, impulsos que se originam na pulsão de morte e retornam ao ego, que não são direcionados para o exterior do corpo pela via muscular.

É interessante notar que o sentimento de culpa gerado pelo movimento pulsional em direção ao ego tem uma face latente inconsciente que não tem a mesma causa do sentimento consciente de culpa. O que se chama de sentimento inconsciente de culpa, uma expressão errônea segundo Freud, é na verdade uma necessidade de punição do próprio ego. Esses impulsos a ele destinados podem revelar um conflito entre as instâncias do aparelho psíquico assim concebido pela psicanálise: ego, id e superego. ${ }^{14} \mathrm{O}$ palco do conflito se encontra justamente no ego, instância que tem uma função conciliadora das três instâncias. $\mathrm{O}$ superego, ou a instância moral, é uma instância comparativa do ego, determina a este último o que seria seu ideal de funcionamento. $\mathrm{O}$ superego se origina tanto na instância das paixões, o id, quanto na realidade. As primeiras moções libidinais do id, bem como alguns elementos exteriores que pertenciam ao superego, são posteriormente introjetados no ego. Desses elementos o ego acaba por extrair seus termos de comparação com o superego, o qual lhe parece então duro e cruel.

O diabo na condição de substituto do pai do pintor evidencia ou ainda torna figurada essa ambivalência de sentimentos amorosos e destrutivos, ambivalência que resulta do conflito entre as instâncias psíquicas. Esses sentimentos são destinados, nessa configuração, a um outro, mas retornam para aquele que os elabora por meio de fantasias que manifestam um sentimento de culpa que permanece inconsciente.

14. Freud, S. Névrose, psychose et perversion. Paris: Puf, 2002, p. 294. 
Ainda que Haizmann tenha permanecido por um período de nove meses em bom estado de saúde mental, podemos observar, pelo seu mau estado psíquico, um agravamento posterior da neurose. Esse estado pode ser descrito em três fases. Numa primeira fase, o pintor padece de alucinações com um cavaleiro que lhe oferece dinheiro pela pintura que havia feito, inclusive uma pintura que retrata a consagração do pacto; depois, o mesmo cavaleiro oferece-lhe a posse de belas mulheres; por fim, oferece-lhe um trono de ouro maciço, do qual ele poderia reinar por toda a eternidade. Numa segunda fase, tem alucinações com o Cristo, que primeiro lhe pede para renunciar a este mundo pecaminoso e depois o ameaça por não ter aceitado a proposta divina; a própria Virgem lhe teria aparecido, rogando-lhe que aceitasse a proposta do filho. Como essas manobras não surtem efeito, Cristo retorna com ameaças que, por fim, fazem com que Haizmann ceda a seus apelos. Numa última fase, observamos alucinações ascéticas e de castigo, por supostos pensamentos de vício e vaidade.

Freud, analisando o percurso relatado pelo pintor em seu diário íntimo, constata que após a morte do pai o pintor busca no estado melancólico a solução para o dilema de seu sustento, retomando uma atividade que lhe assegura meios de subsistência. Mas o pacto com o diabo the custa, em sua perturbada imaginação, a bem-aventurança. Como essa solução não se mostra bem sucedi$\mathrm{da}$, ainda em busca de manutenção da vida, ele procura o auxílio eclesiástico a despeito de sua liberdade. No entanto, é acometido, no curso de sua neurose, por fantasias de culpa e reprovação que, do ponto de vista psicanalítico, fazem parte do impulso destrutivo dirigido ao ego, ainda que sua "neurose apareça como uma escamoteação que encobre um fragmento da séria, mas vulgar luta pela vida". ${ }^{15}$

Quando retornamos ao texto de Patočka, vemos que contrariamente à imortalidade inautêntica, a imortalidade autêntica "se oferece àqueles cujo receio de uma existência absolutamente nega-

15. Freud, S. "Una neurosis demoníaca en el siglo XVII" (1922). In: Obras Completas, Vol. XIX, p. 105. 
tiva suplanta o medo da morte corporal para esperar o que talvez se espere no ponto mais alto da vida: a absolutez da finitude desta vida" ${ }^{16}$ Fausto encontra um comprador que o faz vislumbrar a possibilidade de uma infinitude interior e uma compreensão universal. Com isso ele engrandece seus conhecimentos, leva ao infinito seu poder, "mas deixa escapar ao olhar aquilo que é: o saber como realização ativa da existência". ${ }^{17}$ Fausto se recusa a aceitar o ser como aquilo que ele é, ou seja, como finitude e contingência, e nega, por conseguinte, sua própria existência temporal, passo decisivo para se retirar do movimento da existência humana.

Em o Mundo natural como movimento da existência, Patočka diz que o não se esquivar da tristeza e das dificuldades, não ceder à aspiração instintiva de consolar-se, ou não seguir uma tendência egocêntrica, significa "a possibilidade da existência autêntica, existência autêntica como possibilidade que se realiza". ${ }^{18} \mathrm{E}$ acrescenta que a possibilidade de uma existência autêntica como essa pressupõe que o homem já tenha se enraizado no mundo e pertença a uma comunidade, que se relacione com as coisas e com os outros e se posicione perante as coisas e os outros. Pressupõe, portanto, que o "eu tenha um lugar no seio de uma coletividade determinada que mantenha uma luta permanente por esta posição frente às coisas e frente aos outros" ${ }^{19}$ Nesse sentido, a existência, para Patočka, é movimento, pois ela é realização e atualização objetiva das coisas e não simples representação destas. $\mathrm{O}$ eu é possibilidade de escolha e com isso passa ao ser, não é dado desde o início, mas determinado pela relação com os outros. $\mathrm{Na}$ mesma direção, mas em sentido oposto, ele determina uma relação com os outros que se dá no tempo, ou, melhor dizendo, é "determinado pela nossa temporalidade". ${ }^{20}$

16. Patočka, J. L'ecrivain, son “objet”, p. 130.

17. Idem, p. 133.

18. Patočka, J. Le monde naturel et le movement de l'existence, p. 263.

19. Idem, ibidem.

20. Idem, p. 264. 
Quando Fausto suspende sua temporalidade e age projetando-se sobre as coisas como se não mais pertencesse a este mundo, acaba também se tornando coisa, perde sua identidade humana verdadeira, desconhece os limites entre o seu próprio eu e o do outro, e por isso o ser deixa de ser unidade. Fausto dissolve-se na medida em que impõe seu amor a Margarida. Ao obrigá-la a amá-lo cegamente, acaba com uma relação possível entre os dois, conseqüentemente com a própria existência. Pede a Margarida que o siga, oferece-lhe a "liberdade" da imortalidade junto a ele e a Mefistófeles. Mas ela se recusa: assume a própria desgraça: sabe-se responsável pela morte de sua própria mãe e não lhe resta outra escolha senão a própria morte. Dessa maneira, quando Patočka se refere a uma legitimidade na consciência de culpa está se referindo a uma possibilidade de retorno à identidade humana, à possibilidade de estabelecer relações com os outros e com as coisas num verdadeiro sentido da existência humana: o da liberdade. É a culpa que paradoxalmente o salva, "é essa culpa que revela a impossibilidade de subtrair a vida imediata ao contexto de valores desconhecidos. Impossibilidade que se torna patente quando, acreditando se apoderar da vida, é a morte que se tem". ${ }^{21} \mathrm{E}$ por meio da culpa que Fausto retoma a consciência de seu lugar no mundo: é tentando tirar Margarida da prisão que percebe escaparem de suas mãos a vida alheia e a sua própria, que lhe fogem ao controle. Ao sair da prisão e acatar as palavras de Mefistófeles, Fausto é constrangido a uma nova opção, que seja pela negação de sua liberdade.

Em Freud, ao contrário, como resultado de uma fantasia de culpa o que temos não é uma consciência de culpa, mas a morte, não de outrem, do indivíduo melancólico, a despeito da vontade deste. Acometido de uma neurose "demoníaca", o pintor padece de suas alucinações, inicialmente de gozo, de reprovação e culpa.

Um caso de consciência de culpa poderia, como em Fausto, impedir a morte do pintor, mas não no sentido em que Patočka o coloca: Haizmann não busca atingir o conhecimento máximo, nem tornar sua pintura uma pintura de excelência, apenas, como

21. Patočka, J. L'écrivain, son “objet”, p. 137. 
diz Freud, seu próprio sustento. A psicanálise freudiana não diferencia uma imortalidade autêntica de uma não autêntica, o pacto com o diabo pode ter diversos sentidos psicanalíticos, mas todos são tomados como autênticos. Já para a fenomenologia de Patočka é como se houvesse um sentido autêntico para a vida, sentido que podemos encontrar no último parágrafo de seu texto do mito do pacto com o diabo:

O sentimento de responsabilidade universal não é então uma fusão mística, a fusão, ou a identificação de todos numa simpatia universal. É um sentimento de solidariedade na participação pela verdade e pelo destino humano. $\mathrm{O}$ que significa essa responsabilidade no sentido universal? Não é outra coisa que submeter-se ao julgamento $\mathrm{e}$, portanto, à lei, à comunidade verdadeira e universal; querer ser julgado ao saber que somos cúmplices de todo o mal; querer ter e pagar sua parte de iniqüidade universal, sem retirá-la da esfera privada, numa atitude estética ou lúdica - querer tomar parte da justiça universal como única situação na qual aquela alma como tal possa existir, alma enquanto ser, cuja existência é um excelso que se furta à decadência. ${ }^{22}$

Se na fenomenologia de Patočka temos um sentido verdadeiro e universal para o ser e sua existência, ele deve ser perseguido ativamente tendo em vista uma responsabilidade universal pela qual o ser enquanto unidade compartilha com uma verdadeira comunidade a submissão a uma lei verdadeira e universal. Apenas numa situação em que se tem uma ação responsável de constatação de que "somos cúmplices de todo o mal", ou seja, de que somos apenas inscrição da vida, simples condição vital, é que podemos alcançar o verdadeiro sentido do ser. Dirigir-se para fora da decadência significa encontrar-se em liberdade, poder lutar pela totalidade e pela reconciliação. Nas palavras de Patočka, "o homem é apenas homem como conseqüência de uma dissolução fortemente pronunciada que resulta num conflito - ele não será homem, quer dizer, ser livre, nem se sucumbir como um animal impulsionado

22. Patočka, J. "Le sens du Mythe du pacte avec le diable". In: L'ecrivain, son "objet". Paris: P.O.L., 1992, p. 149. 
pela totalidade, nem se for simplesmente a representação de forças "interiores". ${ }^{23}$

É interessante notar que para Freud não há esse sentido de liberdade que encontramos em Patočka. Como vemos no caso de Haizmann, o homem busca soluções para manter-se vivo, mas essas soluções são determinadas por sua melancolia, pelo conflito de suas instâncias psíquicas internas. A luta pela vida é por si mesma autêntica, o homem é o próprio conflito de forças interiores, move-se pelo desejo e este não revela outra coisa que um conflito de forças pulsionais. O desejo como tentativa de restabelecimento de uma primeira experiência de prazer coloca em movimento o aparelho psíquico, e como ressalta Freud, "somente o desejo e nada mais pode colocar o aparelho psíquico em movimento". ${ }^{24}$ Quando essas forças se fazem representar psiquicamente na consciência, temos um conflito aberto que pode bem ser modificado por forças externas ao indivíduo. Nesse sentido, para a psicanálise freudiana, o homem não é nem pode ser livre, mas faz parte de um mundo que ele tenta controlar seja como resposta aos estímulos que recebe desse mesmo mundo seja como maneira de lidar com os conflitos internos que o assolam. A luta pela vida não é outra coisa que a manutenção da vida, uma disputa interior entre pulsões conflitantes, de vida e de morte, que tem como conseqüência um rodeio para chegar à morte.

Resignar-se à própria finitude não significa, para Freud, o mesmo que liberdade. Para Freud, segundo Binswanger, "o bem e a moral fazem parte de uma força inibitória e restritiva, que condena e que reprime sem possuir uma eficácia originalmente positiva, ou seja, libertária, criativa”. ${ }^{25}$ Isso porque, para a psicanálise

23. Patočka, J. apud Barbaras, R. Le mouvement de l'existence, p. 112.

24. Freud, S. "Interpretacíon de los sueños" (1900). In: . Obras Completas. Vol. V. Buenos Aires: Amorrortu editores, 2003, p. 588. Ou como nos diz Monzani, "o desejo inconsciente só tem uma e única finalidade: realizar sua forma originária, repetir aquilo que foi fonte do prazer e do gozo." Monzani, L. R., "O suplemento e o excesso". In: Folhetim. Folha de São Paulo, 31/08/1986.

25. Binswanger, L. Analyse existentielle et psychanalyse freudienne, discours parcours et Freud. Paris: Gallimard, 1981, p. 204. 
freudiana, as moções pulsionais não são em si boas ou más, elas aparecem como pares de opostos, e têm a capacidade de transformação ao longo da vida. Por exemplo, as pulsões egoístas se modificam em pulsões sociais, os maus instintos em bons e, segundo Freud, "as boas disposições são produzidas por coação". No início da história da humanidade essas disposições seriam produzidas por coação exterior para, posteriormente, serem incorporadas e se transformarem em "disposições hereditárias". ${ }^{26}$

Seria então por uma coação exterior que, para Freud, há o desenvolvimento do aparelho psíquico: "as circunstâncias exteriores são decisivas na constituição psíquica do indivíduo" ${ }^{27}$, particularmente para a formação da instância moral, ou o superego. "Cada criança executa esse processo de transformação que se torna social e moral por ela mesma". ${ }^{28}$ Essa transformação se concretiza pela adição do componente erótico: aprendemos a apreciar o fato de sermos amados como uma vantagem em favor da qual podemos renunciar às outras vantagens. A cultura seria, portanto, o resultado da renúncia à satisfação pulsional, e o homem estaria justamente imerso nesse caldo de cultura em que se enredam a pulsão e a ilusão de satisfação pulsional. "Da tensão entre essas duas forças surgiriam a arte, o mito e a religião". ${ }^{29}$

Já para Patočka, a própria experiência de ser é uma experiência de liberdade: "a experiência da liberdade é um acesso ao ser enquanto ele é, quer dizer, uma abertura para a questão do sentido de seu ser-dado na experiência”. ${ }^{30}$

O homem é apenas homem como conseqüência de uma dissolução que resulta num conflito - ele não seria homem, vale dizer, não

26. Idem, p. 205.

27. Freud, S. "El malestar em la cultura" (1930 [1929]). In: Obras Completas.Vol. XXI. Buenos Aires: Amorrortu editores, 2003, p. 83.

28. FREUD, S. "El porvenir de una ilusión” (1927). In: Obras Completas, Vol.XXI. Buenos Aires: Amorrortu editores, 2003, p. 11.

29. Binswanger, L. Analyse existentielle et psychanalyse freudienne, discours parcours et Freud, p. 207.

30. Barbaras, R. Le mouvement de l'existence, p. 11. 
seria livre, se sucumbisse como animal à impulsão da totalidade ou se fosse simplesmente o representante de forças interiores, objetivantes, que se opõem à totalidade, que se interpõem a ela e a recobrem. ${ }^{31}$

\section{Bibliografia}

BARBARAS, R. Le mouvement de l'existence: Études sur la phénoménologie de Jan Patockka. Chatou: les éditions de La Transparance, 2007.

BINSWANGER, L. Analyse existentielle et psychanalyse freudienne, discours parcours et Freud. Paris: Gallimard, 1981.

FREUD, S. Névrose, psychose et perversion. Paris: Puf, 2002. . Interpretacion de los sueños (1900). In: Obras Completas. Vol.

V. Buenos Aires: Amorrortu editores, 2003. .El malestar em la cultura (1930 [1929]).In: Vol. XXI. Buenos Aires: Amorrortu editores, 2003. . Obras Completas. . El porvenir de una ilusión (1927). In: XXI. Buenos Aires: Amorrortu editores, 2003. . "Una neurosis demoníaca en el siglo XVII" (1922). In:

Obras Completas. Vol. XIX. Buenos Aires: Amorrortu editores, 2003. "Mourning and melancholia". In: The Penguin Freud Reader. London: Penguin books, 2006

MONZANI, L. R. "O suplemento e o excesso". In: Folhetim. Folha de São Paulo, 31/08/1986.

PATOČKA, J. Le monde naturel et le mouvement de l'existence humaine. Paris: Kluwer academic publishers, 1980.

."Le sens du Mythe du pacte avec le diable".In: .L'ecrivain, son "objet". Paris: P.O.L., 1992.

31. Patočka, J. apud Barbaras, R. Le mouvement de l'existence, p. 112. 